\title{
Patients Living With Breast Cancer During the Coronavirus Pandemic: The Role of Family Resilience, Coping Flexibility, and Locus of Control on Affective Responses
}

\author{
Eleonora Brivio ${ }^{1 *}$, Paolo Guiddi', Ludovica Scotto ${ }^{1}$, Alice V. Giudice', Greta Pettini', \\ Derna Busacchio', Florence Didier ${ }^{1}$, Ketti Mazzocco ${ }^{1,2}$ and Gabriella Pravettoni ${ }^{1,2}$ \\ 'Applied Research Unit for Cognitive and Psychological Science, European Institute of Oncology, IRCCS, Milan, Italy, \\ ${ }^{2}$ Department of Oncology and Hemato-Oncology, University of Milan, Milan, Italy
}

\section{OPEN ACCESS}

Edited by:

Changiz Mohiyeddini,

Oakland University William Beaumont School of Medicine, United States

Reviewed by: Annunziata Romeo, University of Turin, Italy

Matilde Taddei,

Fondazione IRCCS Istituto

Neurologico Carlo Besta, Italy

*Correspondence:

Eleonora Brivio

eleonora.brivio@ieo.it

Specialty section: This article was submitted to

Health Psychology,

a section of the journal

Frontiers in Psychology

Received: 29 May 2020 Accepted: 01 December 2020

Published: 14 January 2021

Citation:

Brivio E, Guiddi P, Scotto L, Giudice AV, Pettini G, Busacchio $D$,

Didier F, Mazzocco K and Pravettoni G (2021) Patients Living

With Breast Cancer During

the Coronavirus Pandemic: The Role of Family Resilience, Coping Flexibility, and Locus of Control on Affective

Responses.

Front. Psychol. 11:567230. doi: 10.3389/fpsyg.2020.567230
The coronavirus disease 2019 (COVID-19) pandemic has strongly affected oncology patients. Many screening and treatment programs have been postponed or canceled, and such patients also experience fear of increased risk of exposure to the virus. In many cases, locus of control, coping flexibility, and perception of a supportive environment, specifically family resilience, can allow for positive emotional outcomes for individuals managing complex health conditions like cancer. This study aims to determine if family resilience, coping flexibility, and locus of control can mitigate the negative affect caused by the pandemic and enhance positive affect in breast cancer patients. One hundred and fifty-four female patients with breast cancer completed the Walsh's Family Resilience Questionnaire, the Perceived Ability to Cope With Trauma Scale, the Positive-Negative Affect Schedule, and the Mini Locus of Control Scale. Family resilience and internality of locus of control contribute significantly to positive affective responses. Family resilience is responsible for mitigating the negative affect perceived during the pandemic and is enhanced by external locus of control. Evidence suggests that clinical psychologists should develop and propose programs to support oncology patients' family resilience, coping flexibility, and internal locus of control, allowing for decreased stress and improved adaptability for effectively managing cancer treatment during the pandemic.

Keywords: breast cancer, coronavirus, COVID-19, locus of control, coping flexibility, family resilience, breast cancer patients

\section{INTRODUCTION}

Since late February 2020, Italy has been drastically affected by the coronavirus disease 2019 (COVID-19) pandemic, resulting in approximately 229,300 positive cases and 33,000 deaths (World Health Organization, 2020). The pandemic has required a restructuring of the hospital system and suspension of all non-essential health services to better manage the influx of COVID19 patients while also reducing potential exposure to uninfected patients (Curigliano et al., 2020; van de Haar et al., 2020). The pandemic has also necessitated the implementation of a countrywide 
lockdown - effective at the beginning of March 2020 - including the closure of places previously open to the public, suspension of all non-essential activities, telecommuting requirements for the workforce, and a stay-at-home order for the general population.

Many COVID-19 patients have presented with comorbidities like cardiovascular disease, liver disease, or malignant tumors (Guan et al., 2020; Thakur, 2020; Yang et al., 2020). However, evidence remains unclear if oncology and other immunosuppressed patients are at an increased risk of severe complications from the virus as compared with healthy individuals among the general population (D'Antiga, 2020; Desai et al., 2020). Oncology patients have been more strongly impacted by the pandemic, not only because of the fear and panic of increased risk of infection (Casanova et al., 2020; Mark and Lewis, 2020; Romeo et al., 2020) but also because many treatment and screening programs have been postponed or canceled until the spread of the virus is stabilized, potentially compromising the affective states of these patients. Donovan stated that when traumatic events like cancer diagnoses or emergency situations arise, personal outcomes - adaptation versus maladaptation - are affected by family response (Donovan, 1998). Additionally, the Double ABC-X model (McCubbin and Patterson, 1983) explains that the interaction between the traumatic event and subsequent life stressors is determined by perceptions of family support, coping strategies, and locus of control.

Family resilience is defined as the perceived ability of a family to withstand a crisis which disrupts their normal course of life and can be a protective factor against stress and negative affect (Walsh, 1996). Perceptions of family's role, system of beliefs, values, and behaviors are essential in helping a family member overcome traumatic events (Patterson, 2002). For example, if one family member has been diagnosed with cancer, perceived high levels of family resilience can significantly influence personal outcomes such as medication compliance, rehabilitation, and social or occupational reintegration (Faccio et al., 2018). These resources may also offer support in overcoming challenges like negative emotions linked to heightened perception of risk, mandatory quarantine, and possible postponement of treatments presented by the COVID-19 pandemic (Killgore et al., 2020; Prime et al., 2020; Russell et al., 2020).

Another protective factor is coping flexibility. A literature review by Kashdan and Rottenberg (2010) identified coping flexibility as a vital component of health and adjustment to stressors across a variety of settings. Since the early 1990s, coping flexibility has been associated with improved well-being and success in confronting stress (Lester et al., 1994). Additionally, it is associated with decreased anxiety and depression as well as symptom severity, ultimately increasing overall quality of life (Cheng, 2003; Kato, 2012, 2015). These studies demonstrate that coping flexibility contributes to improved psychological wellbeing, further confirmed by individuals' reports of decreased levels of depression and increased abilities in managing workrelated stress following completion of a coping flexibility intervention (Cheng et al., 2012).

When assuming a situational perspective, a cross-situational view of coping flexibility supports that coping-flexible individuals can adjust their strategies across stressful events (Westman and Shirom, 1995; Murphy, 2001; Thompson et al., 2007). Oncology patients, for example, have already experienced a severe adverse traumatic event - cancer diagnosis and prognosis - which can introduce important emotional consequences (Williams, 2002) and coping challenges (Nipp et al., 2016). Coping flexibility (Oliveri et al., 2019a) is therefore considered a valuable tool that allows such patients to reduce distress (Bonanno et al., 2011) during stressful circumstances (Roussi et al., 2007) like the COVID-19 pandemic. Coping flexibility remains especially vital in reconciling the need to both elaborate the trauma and maintain a positive outlook toward the future after the event has subsided (Bonanno et al., 2008). Oncology patients who can access these coping resources are more likely to endure the pandemic and subsequent lockdown with adequate emotional response (Kaliampos and Roussi, 2018). Examining emotional responses of breast cancer patients during the pandemic can therefore be a preliminary approach to understanding its impact.

Patients' affect during the COVID-19 pandemic is also influenced by locus of control (Romeo et al., 2019), which determines if individuals perceive the events they are experiencing to be driven by external (e.g., circumstances) or internal (e.g., individuals' personality, abilities, etc.) factors (Rotter, 1966). These beliefs influence individuals' cognition, behavior, and affect (Wallston et al., 1978). Evidence has shown that having an internal locus of control is a strong predictor of better psychological adjustment to cancer: behavioral scientists have long been interested in understanding how an individual's locus of control relates to coping and adjustment (Knappe and Pinquart, 2009; Galvin et al., 2018). Recent research highlights that internal locus of control generates positive emotions and lessens negative ones (Crisson and Keefe, 1988; Gupta et al., 2018). Thus, internal locus of control lowers the perceived level of distress (Ryan and Deci, 2008), threat, and depression (Arraras et al., 2002; Goldzweig et al., 2016) while improving the quality of life (Sharif and Khanekharab, 2017; Toscano et al., 2020) among patients.

The literature therefore highlights the role of these variables in reducing the levels of distress and in promoting psychological adjustment. At the moment, there is no empirical evidence on their impact on Italian cancer patients' affects during the first month of the 2020 lockdown. Therefore, the purpose of this paper is to determine if family resilience, coping flexibility, and locus of control can mitigate the negative affect and enhance positive affect in Italian oncology patients during the first month of the COVID-19 pandemic.

\section{MATERIALS AND METHODS}

The study was reviewed and approved by the IEO (Istituto Europeo di Oncologia) Ethic Committee. The patients/participants provided their informed consent to participate in this study.

\section{Procedure}

Participants were eligible for the study if the patient (a) was female, 40-70 years of age at the time of recruitment diagnosis; (b) had a breast cancer diagnosis requiring surgery; (c) is receiving any type of systemic treatment for breast cancer 
regardless of treatment type; and (d) could both read and speak Italian. All patients received their diagnosis in 2019 or later, and all the patients had cancer in stages I-III. Participants were recruited using a convenience sampling method during the COVID-19 quarantine. Participants were a pool of IEO patients who at the time of the admission gave their availability to participate to research studies and were at the time enrolled in other research projects. All eligible patients were contacted through email or telephone, on the preferred method of contact they gave for the study. A message was included to invite them to take part to the study and an anonymous link to the survey was included.

The survey was hosted by Qualtrics, and an anonymous link was made available to the patients. Participation in the study was voluntary, and patients could withdraw from the study at any time. Participants signed consent forms and completed questions regarding sociodemographic characteristics as well as questions regarding family resilience, coping flexibility in trauma, locus of control, and positive and negative affect. The questionnaire was available from March 19th to March 31st, 2020, starting 4 weeks after the partial lockdown (school closure) and 10 days after the full lockdown (closure of all non-essential businesses and movement restrictions) in Italy.

\section{Participants}

Out of a total of 250 women with breast cancer, 181 started the questionnaire, and 154 completed the questionnaire. Mean age was 51.07 ( $\mathrm{SD}=7.93)$. Thirty-seven $(20.4 \%)$ were single and 146 (79.6\%) were in a stable relationship (married or cohabiting), and 127 (70.2\%) had children. Regarding educational levels, 40.3\% $(n=73)$ of the participants possessed a high school diploma, $7.2 \%$ $(n=13)$ achieved a bachelor's degree, and 26\% $(n=47)$ achieved a higher specialization. One hundred and twenty-five participants $(69.1 \%)$ were still receiving systemic treatment that included chemotherapy, radiotherapy, and/or endocrinological treatment at the time of the survey. All percentages were calculated for total available cases for each demographic variable.

\section{Measures}

After completing the sociodemographic form, participants were asked to fill the following sections:

Family resilience (FR) was measured with the Italian version of the Walsh's Family Resilience Questionnaire (Rocchi et al., 2017), a 26-item questionnaire, on a five-point Likert scale ( 1 = "not at all"; 5 = "completely agree") assessing the three dimensions of family resilience: shared beliefs and support, family organization and interaction, and utilization of social resources. Shared beliefs and support (FR_SBS) includes values, beliefs, and attitudes, establishing a set of shared suppositions that activate emotional responses, form decisions, and orientate action (15 items). Family organization and interaction (FR_FOI) is the perceived family capacity to adapt and identify collaborative solutions to manage crises and avoid conflicts (eight items). Utilization of social resources (FR_USR) indicates individuals' perceived ability of the family to harness support from social and institutional organizations (three items).
Coping flexibility (CF) was measured with the Italian version of the Perceived Ability to Cope With Trauma Scale (PACT) (Saita et al., 2017), which examines the broad categories of coping behaviors in response to potentially traumatic experiences. The Italian version of the PACT differs from the original one for the number of items and dimensions: The questionnaire was composed of 14 items which asked participants to rate their ability to use different coping strategies on a seven-point scale ( 1 = "not at all able"; 7 = "extremely able"). Forward focus (CF_FF, nine items) is the component that assesses coping abilities related to maintaining plans and goals, attending to the needs of others, thinking optimistically, remaining calm, reducing painful emotions, and laughing. The trauma focus subscale (CF_TF, five items) explores the ability to fully experience the emotional and cognitive significance of a stressful, and potentially traumatic, event.

Locus of control (LOC) was measured with the Italian version of the six-item Mini Locus of Control Scale (MLCS) (Perussia and Viano, 2008). It is a self-reported scale that investigates locus of control based on three factors: chance (LOC_C, two items), powerful of others (LOC_PO, two items), and internality (LOC_I, two items). The questionnaire is composed of six items on a four-point Likert scale ( 1 = "not at all"; 4 = "completely agree").

Affect was measured through the Positive-Negative Affect Schedule (PANAS) (Terraciano et al., 2003). This scale is comprised of two 10-item mood scales and was developed to provide brief measures of positive and negative affect. Subjects are asked to rate each peculiar emotion experienced within a specified time period, with reference to a five-point scale ( 1 = "very slightly or not at all"; 5 = "very much"). The specified time period in this case was 15 days before the questionnaire was completed, taking place during the COVID-19 pandemic in Italy.

\section{Statistical Strategy}

Demographic variables were described using descriptive statistics. Before proceeding with the regression analyses, assumptions were checked and the data met the requirement for the analysis. Two stepwise regression analyses (forward method with removal test for the least useful predictor) were conducted with dimensions of family resilience, dimensions of locus of control (chance, powerful others, internality), and coping flexibility as predictors, with positive and negative affect as outcome variables. Variance inflation factors (VIF) revealed acceptable values of collinearity between independent variables and are included in Table 2.

\section{RESULTS}

Table 1 shows the mean, standard deviations, and correlations among variables for both the regression outcome variables. Positive affect correlates adequately with all the other variables included in the analysis, except for the chance dimension of the locus of control (LOC_C). Negative affect is significantly correlated with all the variables considered. The chance dimension of locus of control (LOC_C) is not connected with the trauma focus factor of coping flexibility (CF_TF). Other 
non-correlated variables are two dimensions of locus of control: internality (LOC_I) and chance (LOC_C). Please see Table 1 for detailed results of the correlation analyses.

The first stepwise multiple regression was conducted to evaluate whether the dimensions of family resilience, coping flexibility, and locus of control were necessary to predict positive affect. The analyses generated three models (please see Table 2 for details). The final model of the regression analysis accounted for $45.4 \%$ of the variance of positive effect with three predictors (family organization and interaction of family resilience, the trauma focus subscale of coping flexibility, and internality of locus of control) with a significant improvement from previous models. Other variables - chance of locus of control (LOC_C: $t=-0.433, p=0.666)$, powerful of others of locus of control (LOC_PO: $t=0.101, p=0.902$ ), forward focus of coping flexibility (CF_FF: $t=1.179, p=0.240$ ), shared beliefs and support of family resilience (FR_SBS: $t=1.007, p=0.316$ ), and utilization of social resources of family resilience (FR_USR: $t=1.417, p=0.159$ ) did not enter the model at any stage (refer to model 3 for values reported).

The second stepwise multiple regression was conducted to evaluate whether the same variables were necessary to predict negative affect. Three models were calculated (please see Table 2). The multiple correlation coefficient for the final model was 0.57 , indicating that approximately $33.1 \%$ of the variance of positive affect could be accounted for by family organization and interaction of family resilience, the powerful of others dimension of locus of control, and internality of locus of control, with a significant improvement from the other models. Internality of locus of control (LOC_I: $t=-0.454, p=0.650$ ), forward focus in coping flexibility (CF_FF: $t=-1.090, p=0.278$ ), trauma focus subscale of coping flexibility (CF_TF: $t=1.117, p=0.266$ ), shared beliefs and support of family resilience (FR_SBS: $t=-0.459$, $p=0.647$ ), and utilization of social resources of family resilience (FR_URS: $t=0.307, p=0.759$ ) did not enter the model at any stage (refer to model 3 for values reported).

\section{DISCUSSION}

The data highlights that family resilience, coping flexibility, and locus of control contribute significantly in managing the positive and negative affect in patients with cancer during the COVID19 pandemic in Italy. Results show that one dimension of each

TABLE 1 | Means, standard deviations, and correlations for all the variables considered.

\begin{tabular}{|c|c|c|c|c|c|c|c|c|c|c|}
\hline & Mean & $\begin{array}{c}\text { Std. } \\
\text { deviation }\end{array}$ & 1. & 2. & 3. & 4. & 5. & 6. & 7. & 8. \\
\hline Positive affect & 2.979 & 0.778 & $0.385^{\star \star}$ & -0.106 & $-0.178^{\star}$ & $0.560^{\star \star}$ & $0.481^{\star \star}$ & $0.499^{\star \star}$ & $0.603^{\star \star}$ & $0.408^{\star \star}$ \\
\hline 1. Locus of control_internality (LOC_I) & 3.302 & 0.410 & & 0.053 & $-0.167^{\star}$ & $0.402^{\star \star}$ & $0.302^{\star \star}$ & $0.256^{\star}$ & $0.276^{\star \star}$ & $0.139^{*}$ \\
\hline 2. Locus of control_chance (LOC_C) & 2.656 & 0.678 & & & $0.375^{\star \star}$ & $-0.155^{\star}$ & -0.085 & -0.122 & $-0.158^{\star}$ & -0.086 \\
\hline $\begin{array}{l}\text { 3. Locus of control_powerful of others } \\
\text { (LOC_PO) }\end{array}$ & 1.753 & 0.622 & & & & $-0.280^{\star \star}$ & -0.095 & $-0.384^{\star \star}$ & $-0.289^{\star \star}$ & $-0.190^{\star}$ \\
\hline $\begin{array}{l}\text { 4. Coping flexibility_forward focus } \\
\text { (CF_FF) }\end{array}$ & 5.049 & 0.920 & & & & & $0.631^{\star \star}$ & $0.490^{\star \star}$ & $0.654^{\star \star}$ & $0.380^{\star \star}$ \\
\hline $\begin{array}{l}\text { 5. Coping flexibility_trauma focus } \\
\text { (CF_TF) }\end{array}$ & 5.003 & 0.871 & & & & & & $0.332^{\star \star}$ & $0.438^{\star \star}$ & $0.340^{\star \star}$ \\
\hline $\begin{array}{l}\text { 6. Family resilience_shared beliefs and } \\
\text { support (FR_SBS) }\end{array}$ & 56.630 & 9.345 & & & & & & & $0.742^{\star *}$ & $0.532^{\star \star}$ \\
\hline $\begin{array}{l}\text { 7. Family resilience_family organization } \\
\text { and interaction (FR_FOI) }\end{array}$ & 28.721 & 4.758 & & & & & & & & $0.516^{\star \star}$ \\
\hline $\begin{array}{l}\text { 8. Family resilience_utilization of social } \\
\text { resources (FR_USR) }\end{array}$ & 9.461 & 1.961 & & & & & & & & \\
\hline Negative affect & 2.150 & 0.710 & $-0.170^{\star}$ & $0.297^{\star \star}$ & $0.413^{\star *}$ & $-0.399^{\star \star}$ & $-0.138^{\star}$ & $-0.419^{\star \star}$ & $-0.481^{\star \star}$ & $-0.241^{*}$ \\
\hline 1. Locus of control_internality (LOC_I) & 3.301 & 0.409 & & 0.053 & $-0.167^{\star}$ & $0.402^{\star \star}$ & $0.302^{\star \star}$ & $0.256^{\star}$ & $0.276^{\star \star}$ & $0.139^{\star}$ \\
\hline 2. Locus of control_chance (LOC_C) & 2.655 & 0.677 & & & $0.375^{\star \star}$ & $-0.155^{\star}$ & -0.085 & -0.122 & $-0.158^{\star}$ & -0.086 \\
\hline $\begin{array}{l}\text { 3. Locus of control_powerful of others } \\
\text { (LOC_PO) }\end{array}$ & 1.753 & 0.621 & & & 1.000 & $-0.280^{\star \star}$ & -0.095 & $-0.384^{\star \star}$ & $-0.289^{\star \star}$ & $-0.190^{\star}$ \\
\hline $\begin{array}{l}\text { 4. Coping flexibility_forward focus } \\
\text { (CF_FF) }\end{array}$ & 5.049 & 0.919 & & & & & $0.631^{\star \star}$ & $0.490^{\star \star}$ & $0.654^{\star \star}$ & $0.380^{\star \star}$ \\
\hline $\begin{array}{l}\text { 5. Coping flexibility_trauma focus } \\
\text { (CF_TF) }\end{array}$ & 5.003 & 0.870 & & & & & & $0.332^{\star \star}$ & $0.438^{\star \star}$ & $0.340^{* *}$ \\
\hline $\begin{array}{l}\text { 6. Family resilience_shared beliefs and } \\
\text { support (FR_SBS) }\end{array}$ & 56.629 & 9.345 & & & & & & & $0.742^{\star \star}$ & $0.532^{* \star}$ \\
\hline $\begin{array}{l}\text { 7. Family resilience_family organization } \\
\text { and interaction (FR_FOI) }\end{array}$ & 28.720 & 4.757 & & & & & & & & $0.516^{\star \star}$ \\
\hline $\begin{array}{l}\text { 8. Family resilience_utilization of social } \\
\text { resources (FR_USR) }\end{array}$ & 9.461 & 1.960 & & & & & & & & \\
\hline
\end{tabular}

$N=154 .{ }^{*}$ indicates significant values at $p<0.000,{ }^{*}$ indicates significant values at $p<0.05$. 
TABLE 2 | Regression models, beta values and collinearity statistics for the two regression analyses.

\begin{tabular}{|c|c|c|c|c|c|c|c|c|c|c|c|c|}
\hline & \multicolumn{2}{|c|}{$\begin{array}{l}\text { Unstandardized } \\
\text { coefficients }\end{array}$} & \multicolumn{3}{|c|}{$\begin{array}{l}\text { Standardized } \\
\text { coefficients }\end{array}$} & \multirow[t]{2}{*}{$\boldsymbol{R}$} & \multirow[t]{2}{*}{$R^{2}$} & \multicolumn{4}{|c|}{ Model change } & \multirow{2}{*}{$\begin{array}{l}\text { Collinearity statistics } \\
\text { VIF }\end{array}$} \\
\hline & $B$ & $\begin{array}{l}\text { Standard } \\
\text { error }\end{array}$ & Beta & $t$ test & Sig. & & & F change & Df1 & Df2 & Sig. F change & \\
\hline \multicolumn{13}{|l|}{ Outcome: positive affect } \\
\hline 1 (Constant) & 0.0148 & 0.308 & & 0.481 & 0.631 & & & & & & & \\
\hline $\begin{array}{l}\text { Family resilience_family } \\
\text { organization and interaction } \\
\text { (FR_FOI) }\end{array}$ & -0.099 & 0.011 & 0.603 & 9.308 & 0.000 & 0.603 & 0.363 & 86.639 & 1 & 152 & 0.000 & 1.000 \\
\hline 2 (Constant) & -0.501 & 0.338 & & -1.481 & 0.140 & & & & & & & \\
\hline $\begin{array}{l}\text { Family resilience_family } \\
\text { organization and interaction } \\
\text { (FR_FOI) }\end{array}$ & 0.079 & 0.011 & 0.485 & 7.040 & 0.000 & & & & & & & 1.273 \\
\hline $\begin{array}{l}\text { Coping flexibility_trauma focus } \\
\text { (CF_TF) }\end{array}$ & 0.240 & 0.062 & 0.808 & 3.909 & 0.000 & 0.649 & 0.442 & 15.28 & 1 & 151 & 0.00 & 1.237 \\
\hline 3 (Constant) & -1.354 & 0.435 & & -3.110 & 0.002 & & & & & & & \\
\hline $\begin{array}{l}\text { Family resilience_family } \\
\text { organization and interaction } \\
\text { (FR_FOI) }\end{array}$ & 0.074 & 0.011 & 0.450 & 6.616 & 0.000 & & & & & & & 1.273 \\
\hline $\begin{array}{l}\text { Coping flexibility_trauma focus } \\
\text { (CF_TF) }\end{array}$ & 0.202 & 0.061 & 0.226 & 3.296 & 0.001 & & & & & & & 1.294 \\
\hline $\begin{array}{l}\text { Locus of control_internality } \\
\text { (LOC_l) }\end{array}$ & 0.365 & 0.122 & 0.192 & 2.999 & 0.003 & 0.674 & 0.454 & 8.994 & 1 & 150 & 0.003 & 1.132 \\
\hline \multicolumn{13}{|l|}{ Outcome: negative affect } \\
\hline 1 (Constant) & 4.212 & 0.309 & & 13.621 & 0.000 & & & & & & & \\
\hline $\begin{array}{l}\text { Family resilience_family } \\
\text { organization and interaction } \\
\text { (FR_FOI }\end{array}$ & -0.072 & 0.011 & -0.481 & -6.756 & 0.000 & 0.481 & 0.231 & 45.647 & 1 & 152 & 0.000 & 1.000 \\
\hline 2 (Constant) & 3.241 & 0.372 & & 8.721 & 0.000 & & & & & & & \\
\hline $\begin{array}{l}\text { Family resilience_family } \\
\text { organization and interaction } \\
\text { (FR_FOI }\end{array}$ & -0.059 & 0.011 & -0.394 & -5.595 & 0.000 & & & & & & & 1.091 \\
\hline $\begin{array}{l}\text { Locus of control_powerful of } \\
\text { others (LOC_PO) }\end{array}$ & 0.342 & 0.081 & 0.300 & 4.252 & 0.000 & 0.560 & 0.313 & 18.078 & 1 & 151 & 0.000 & 1.091 \\
\hline 3 (Constant) & 2.912 & 0.404 & & 7.216 & 0.000 & & & & & & & \\
\hline $\begin{array}{l}\text { Family resilience_family } \\
\text { organization and interaction } \\
\text { (FR_FOI }\end{array}$ & -0.058 & 0.010 & -0.386 & -5.530 & 0.000 & & & & & & & 1.094 \\
\hline $\begin{array}{l}\text { Locus of control_powerful of } \\
\text { others (LOC_PO) }\end{array}$ & 0.283 & 0.085 & 0.248 & 3.333 & 0.000 & & & & & & & 1.242 \\
\hline $\begin{array}{l}\text { Locus of control_chance } \\
\text { (LOC_C) }\end{array}$ & 0.150 & 0.076 & 0.143 & 1.983 & 0.049 & 0.575 & 0.317 & 3.933 & 1 & 150 & & 1.167 \\
\hline
\end{tabular}

Regression models, beta values and collinearity statistics for the two regression analyses.

considered construct contributes to positive affect levels. Family organization and interaction (FR_FOI) is the main predictor for positive affect, as it is possible that the pandemic required patients and their family to adapt their previous organizational and interactive patterns to cope with the mandatory and prolonged cohabitation necessitated by the lockdown and to discover new ways of managing the patient's cancer during the public health crisis, as suggested by colleagues (Killgore et al., 2020; Prime et al., 2020; Russell et al., 2020). It is noteworthy that family organization and interaction (FR_FOI) also mitigates negative affect, as its standardized beta value is negative, which likely occurred because patients who perceive higher levels of family organization and interaction (FR_FOI) manage the requirement of the crisis more efficiently and, thus, experience more positive affect and less negative affect. Furthermore, family organization and interaction (FR_FOI) serves as a protective factor from negative emotions, confirming previous findings indicating that positive and negative emotional states can happen during a crisis simultaneously (Fredrickson et al., 2003; Terraciano et al., 2003; Weber, 2010).

Positive states are also enhanced by the Trauma Focus Scale of PACT, which provides that the perceived ability to focus on processing the trauma focus subscale of coping flexibility (CF_TF) is associated with positive states. The ability to focus on trauma helps personal reorganization (Comer et al., 2014; Sahar and Muzaffar, 2017), demonstrating that this result appears 
to confirm that the focus on elaborating traumatic events, both individually on the trauma focus subscale of coping flexibility $\left(\mathrm{CF}_{-} \mathrm{TF}\right)$ and as a family about organization and interaction (FR_FOI), helps activate a more positive outlook and think realistically about COVID-19 without using strategies of denial and avoidance or feeling overwhelmed. Experiencing positive emotions in the wake of a traumatic event is particularly important, as it allows individuals to evoke powerful changes in their emotional trajectory (Fredrickson, 1998, 2000). The literature highlights how this type of coping can moderate the impact of heightened trauma exposure (Romero et al., 2015; Juanjuan et al., 2020).

As previously mentioned, family organization and interaction (FR_FOI) is also responsible for mitigating the negative affect generated by the pandemic, which is instead enhanced by two dimensions of external locus of control: chance of locus of control (LOC_C) and powerful of others of locus of control (LOC_PO). When persons believe they have no control over a situation and rely on chance or others to decide how to act, they show higher levels of negative emotions. This potentially results from the perceived lack of agency in the course of their lives and could be related to a "learned helplessness condition." Literature supports that learned helplessness affects personal resilience and distress management (Mikulincer, 1989; Smallheer et al., 2018). Learned helplessness is a consequence of a perception of scarce personal power over the situation and may result in anxiety, depression, and PTSD (Klein and Seligman, 1976; Akca, 2011; Hammack et al., 2012). This is particularly relevant since coping flexibility does not enter the model with negative affect as an outcome. Additionally, a negative locus of control may affect the ability to access personal coping abilities, which allow persons to activate strategies and tactics (Fresco et al., 2006) to individually deal with the negative event and associated negative affect. The perception of good family support and the family's ability to autoregulate its resources may compensate for these processes of learned helplessness and aid patients through the crisis.

\section{CONCLUSION}

These considerations are limited. The models explain $44 \%$ of the variance of positive affect and 33\% of negative affect produced by the pandemic. There may be other variables that moderate or mediate positive and negative affect, such as health locus of control, dyadic support, relationship closeness, emotional carrying capacity, personality traits, and self-efficacy (Cheng, 2003; Fresco et al., 2006).

Another limitation is that affect is a time-limited outcome. It refers to an affective state that may resolve itself in a short time, and requires constant monitoring of patients to verify if especially negative affective states become more persistent as the COVID-19 crisis continues and transform into more stable psychological conditions such as distress, depression, and anxiety or into optimism and positive outlooks. For example, acute stress disorder (ASD) can occur immediately after the traumatic event and last for less than a month (Weber, 2010). Essentially, a person with ASD can present with stress reactions between 2 days and 4 weeks after experiencing a traumatic event (Smith et al., 1999).
One more limitation regarding the affect is that in this study it was not possible to measure the emotional effects of cancer alone (e.g., a baseline before the pandemic). It is not possible to clearly differentiate the emotional effects of the pandemic and of the patient's cancer, even though the participants were asked to refer to their experience about the pandemic in the previous 15 days. Results are therefore to be taken with caution.

Future studies should also consider the contribution of demographic variables (e.g., parental and relationship status) to the emotional well-being of the patients during critical times, such as the present pandemic.

While this evidence is limited, it can be applied to structuring clinical interventions for both the present and near future as well as for avoiding more serious psychological consequences, as suggested by colleagues from Wuhan (Mei et al., 2020). Clinical psychologists should develop and propose programs to support oncology patients' adjustment and empowerment (Bryant et al., 1999; Bailo et al., 2019), not only during stressful events but also during follow-ups for further monitoring, as suggested by an emergency psychology approach. Interventions, in particular, should address the "patients' strategies" (Arnaboldi et al., 2020) to organize and regulate their family organization and interactions; to stay in the moment and think concretely about their choices, behaviors, and emotions during the crisis, and to make them feel more pro-active during the crisis in relation to their cancer and the crisis itself (Stephens et al., 2013; Ramezani and Gholtash, 2015; Oliveri et al., 2019b). These foci of attention could result in patients that are less prone to negative affect and are able to make more effective decisions about their cancer effectively during this pandemic.

\section{DATA AVAILABILITY STATEMENT}

The raw data supporting the conclusions of this article will be made available by the authors, without undue reservation.

\section{ETHICS STATEMENT}

The study was reviewed and approved by the IEO (Istituto Europeo di Oncologia) Ethics Committee (ID 2612). The patients/participants provided their informed consent to participate in this study.

\section{AUTHOR CONTRIBUTIONS}

EB and PG run the analyses. EB, PG, and LS wrote the first draft of the manuscript. EB, PG, LS, AVG, DB, FD, and GPe contributed to the literature search. LS, AVG, DB, FD, and GPe handled the data collection. KM and GPr supervised the research. EB acted as corresponding author. All authors contributed to the ideation and design of the research and to the revisions of the manuscript.

\section{FUNDING}

EB was supported by a grant from the Fondazione Umberto Veronesi. 


\section{REFERENCES}

Akca, F. (2011). The relationship between test anxiety and learned helplessness. Soc. Behav. Pers. 39, 101-111. doi: 10.2224/sbp.2011.39.1.101

Arnaboldi, P., Oliveri, S., Vergani, L., Marton, G., Guiddi, P., Busacchio, D., et al. (2020). The clinical-care focused psychological interview (CLiC): a structured tool for the assessment of cancer patients' needs. Ecancermedicalscience 14:1000. doi: 10.3332/ecancer.2020.1000

Arraras, J. I., Wright, S. J., Jusue, G., Tejedor, M., and Calvo, J. I. (2002). Coping style, locus of control, psychological distress and pain-related behaviours in cancer and other diseases. Psychol. Health Med. 7, 181-187. doi: 10.1080/ 13548500120116139

Bailo, L., Guiddi, P., Vergani, L., Marton, G., and Pravettoni, G. (2019). The patient perspective: investigating patient empowerment enablers and barriers within the oncological care process. Ecancermedicalscience 13:912. doi: 10.3332/ ecancer.2019.912

Bonanno, G. A., Ho, S. M., Chan, J. C., Kwong, R. S., Cheung, C. K., and Wong, C. P., et al. (2008). Psychological resilience and dysfunction among hospitalized survivors of the SARS epidemic in Hong Kong: a latent class approach. Health Psychol. 27, 659-667. doi: 10.1037/0278-6133.27.5.659

Bonanno, G. A., Pat-Horenczyk, R., and Noll, J. (2011). Coping flexibility and trauma: the perceived ability to cope with trauma (PACT) scale. Psychol. Trauma 3, 117-129. doi: 10.1037/a0020921

Bryant, R. A., Sackville, T., Dangh, S. T., Moulds, M., and Guthrie, R. (1999). Treating acute stress disorder: an evaluation of cognitive behavior therapy and supportive counseling techniques. Am. J. Psychiatry 156, 1780-1786. doi: 10.1176/ajp.156.11.1780

Casanova, M., Bagliacca, E. P., Silva, M., Patriarca, C., Veneroni, L., Clerici, C. A., et al. (2020). How young patients with cancer perceive the Covid-19 (coronavirus) epidemic in Milan, Italy: is there room for other fears? Pediatr. Blood Cancer 67:e28318. doi: 10.1002/pbc.28318

Cheng, C. (2003). Cognitive and motivational processes underlying coping flexibility: a dual-process model. J. Pers. Soc. Psychol. 84, 425-438. doi: 10.1037/ 0022-3514.84.2.425

Cheng, C., Kogan, A., and Chio, J. H. M. (2012). The effectiveness of a new, coping flexibility intervention as compared with a cognitive-behavioural intervention in managing work stress. Work Stress 26, 272-288. doi: 10.1080/02678373.2012. 710369

Comer, J. S., Dantowitz, A., Chou, T., Edson, A. L., Elkins, R. M., Kerns, C., et al. (2014). Adjustment among area youth after the Boston Marathon bombing and subsequent manhunt. Pediatrics 134, 7-14. doi: 10.1542/peds.2013-4115

Crisson, J. E., and Keefe, F. J. (1988). The relationship of locus of control to pain coping strategies and psychological distress in chronic pain patients. Pain 35, 147-154. doi: 10.1016/0304-3959(88)90222-9

Curigliano, G., Cardoso, M. J., Poortmans, P., Gentilini, O., Pravettoni, G., Mazzocco, K., et al. (2020). Recommendations for triage, prioritization and treatment of breast cancer patients during the COVID-19 pandemic. Breast 52, 8-16.

D'Antiga, L. (2020). Coronaviruses and immunosuppressed patients: the facts during the third epidemic. Liver Transpl. 26, 832-834. doi: 10.1002/lt.25756

Desai, A., Sachdeva, S., Parekh, T., and Desai, R. (2020). COVID-19 and cancer: lessons from a pooled meta-analysis. JCO Glob. Oncol. 6, 557-559. doi: 10.1200/ GO.20.00097

Donovan, D. M. (1998). "Continuing care: promoting the maintenance of change," in Applied Clinical Psychology. Treating Addictive Behaviors, eds W. R. Miller and N. Heather (New York, NY: Plenum Press), 317-336. doi: 10.1007/978-14899-1934-2_23

Faccio, F., Renzi, C., Giudice, A. V., and Pravettoni, G. (2018). Family resilience in the oncology setting: development of an integrative framework. Front. Psychol. 9:666. doi: 10.3389/fpsyg.2018.00666

Fredrickson, B. L. (1998). Cultivated emotions: parental socialization of positive emotions and self-conscious emotions. Psychol. Inq. 9, 279-281. doi: 10.1207/ s15327965pli0904_4

Fredrickson, B. L. (2000). Cultivating positive emotions to optimize health and well-being. Prev. Treat. 3:1. doi: 10.1037/1522-3736.3. 1.31a

Fredrickson, B. L., Tugade, M. M., Waugh, C. E., and Larkin, G. R. (2003). What good are positive emotions in crisis? A prospective study of resilience and emotions following the terrorist attacks on the United States on September 11th, 2001. J. Pers. Soc. Psychol. 84, 365-376.

Fresco, D. M., Williams, N. L., and Nugent, N. R. (2006). Flexibility and negative affect: examining the associations of explanatory flexibility and coping flexibility to each other and to depression and anxiety. J. Cogn. Psychother. 30, 201-210. doi: 10.1007/s10608-006-9019-8

Galvin, B. M., Randel, A. E., Collins, B. J., and Johnson, R. E. (2018). Changing the focus of locus (of control): a targeted review of the locus of control literature and agenda for future research. J. Organ. Behav. 39, 820-833. doi: 10.1002/job.2275

Goldzweig, G., Hasson-Ohayon, I., Alon, S., and Shalit, E. (2016). Perceived threat and depression among patients with cancer: the moderating role of health locus of control. Psychol. Health Med. 21, 601-607. doi: 10.1080/13548506.2016. 1140902

Guan, W. J., Liang, W. H., Zhao, Y., Liang, H. R., Chen, Z. S., Li, Y. M., et al. (2020). Comorbidity and its impact on 1590 patients with Covid-19 in China: a nationwide analysis. Eur. Respir. J. 55:2000547. doi: 10.1183/13993003.005472020

Gupta, P. D., Bhattacharya, S., Sheorey, P., and Coelho, P. (2018). Relationship between onboarding experience and turnover intention: intervening role of locus of control and self-efficacy. Ind. Commer. Train. 50, 61-80. doi: 10.1108/ ICT-03-2017-0023

Hammack, S. E., Cooper, M. A., and Lezak, K. R. (2012). Overlapping neurobiology of learned helplessness and conditioned defeat: implications for PTSD and mood disorders. Neuropharmacology 62, 565-575. doi: 10.1016/j.neuropharm. 2011.02.024

Juanjuan, L., Santa-Maria, C. A., Hongfang, F., Lingcheng, W., Pengcheng, Z., Yuanbing, X., et al. (2020). Patient-reported outcomes of patients with breast cancer during the COVID-19 outbreak in the epicenter of China: a crosssectional survey study. Clin. Breast Cancer 20, e651-e662. doi: 10.1016/j.clbc. 2020.06.003

Kaliampos, A., and Roussi, P. (2018). Quality of partner support moderates positive affect in patients with cancer. Psychooncology 27, 1298-1304. doi: 10.1002/pon. 4672

Kashdan, T. B., and Rottenberg, J. (2010). Psychological flexibility as a fundamental aspect of health. Clin. Psychol. Rev. 30, 865-878. doi: 10.1016/j.cpr.2010.03.001

Kato, T. (2012). Development of the coping flexibility scale: evidence for the coping flexibility hypothesis. J. Couns. Psychol. 59, 262-273. doi: 10.1037/a0027770

Kato, T. (2015). Testing of the coping flexibility hypothesis based on the dual-process theory: relationships between coping flexibility and depressive symptoms. Psychiatry Res. 230, 137-142. doi: 10.1016/j.psychres.2015.07.030

Killgore, W. D. S., Taylor, E. C., Cloonan, S. A., and Dailey, N. S. (2020). Psychological resilience during the COVID-19 lockdown. Psychiatry Res. 291:113216. doi: 10.1016/j.psychres.2020.113216

Klein, D. C., and Seligman, M. E. (1976). Reversal of performance deficits and perceptual deficits in learned helplessness and depression. J. Abnorm. Psychol. 85, 11-26. doi: 10.1037//0021-843x.85.1.11

Knappe, S., and Pinquart, M. (2009). Tracing criteria of successful aging? Health locus of control and well-being in older patients with internal diseases. Psychol. Health Med. 14, 201-212. doi: 10.1080/13548500802385717

Lester, N., Smart, L., and Baum, A. (1994). Measuring coping flexibility. Psychol. Health 9, 409-424. doi: 10.1080/08810.1080/ 0887044940840746870449408407468

Mark, A., and Lewis, M. D. (2020). Between Scylla and Charybdis-oncologic decision making in the time of Covid-19. N. Engl. J. Med. 382, 2285-2287. doi: 10.1056/NEJMp2006588

McCubbin, H. I., and Patterson, J. M. (1983). The family stress process: the double ABCX model of adjustment and adaptation. Marriage Fam. Rev. 6, 7-37.

Mei, H., Dong, X., Wang, Y., Tang, L., and Hu, Y. (2020). Managing patients with cancer during the COVID-19 pandemic: frontline experience from Wuhan. Lancet Oncol. 21, 634-636. doi: 10.1016/S1470-2045(20)30238-2

Mikulincer, M. (1989). Coping and learned helplessness: effects of coping strategies on performance following unsolvable problems. Eur. J. Pers. 3, 181-194. doi: 10.1002/per.2410030304

Murphy, B. A. (2001). Coping Strategies used by Athletes to Cope with an Upcoming Athletic Event. Master's thesis, ProQuest Information \& Learning, Ann Arbor, MI.

Nipp, R. D., El-Jawahri, A., Fishbein, J. N., Eusebio, J., Stagl, J. M., Gallagher, E. R., et al. (2016). The relationship between coping strategies, quality of life, 
and mood in patients with incurable cancer. Cancer 122, 2110-2116. doi: 10 . 1002/cncr.30025

Oliveri, S., Arnaboldi, P., Pizzoli, S. F. M., Faccio, F., Giudice, A. V., Sangalli, C., et al. (2019a). PTSD symptom clusters associated with short-and long-term adjustment in early diagnosed breast cancer patients. Ecancermedicalscience 13:917. doi: 10.3332/ecancer.2019.917

Oliveri, S., Scotto, L., Ongaro, G., Triberti, S., Guiddi, P., and Pravettoni, G. (2019b). "You do not get cancer by chance": communicating the role of environmental causes in cancer diseases and the risk of a "guilt rhetoric". Psychooncology 28, 2422-2424.

Patterson, J. M. (2002). Integrating family resilience and family stress theory. J. Marriage Fam. 64, 349-360. doi: 10.1111/j.1741-3737.2002.00349.x

Perussia, F., and Viano, R. (2008). "Mini locus of control scale," in Teorie e Metodi della Psicologia Italiana. Tendenze Attuali, eds S. Di Nuovo and G. Sprini (Milano: Angeli Press), 457-468.

Prime, H., Wade, M., and Browne, D. T. (2020). Risk and resilience in family well-being during the COVID-19 pandemic. Am. Psychol. 75, 631-643. doi: 10.1037/amp0000660

Ramezani, S. G., and Gholtash, A. (2015). The relationship between happiness, self-control and locus of control. Int. J. Educ. Psychol. Res. 1, 100-104. doi: 10.4103/2395-2296.152222

Rocchi, S., Ghidelli, C., Burro, R., Vitacca, M., Scalvini, S., Della Vedova, A. M., et al. (2017). The Walsh family resilience questionnaire: the Italian version. Neuropsychiatr. Dis. Treat. 13, 2987-2999.

Romeo, A., Castelli, L., and Franco, P. (2020). The effect of COVID-19 on radiation oncology professionals and patients with cancer: from trauma to psychological growth. Adv. Radiat. Oncol. 5, 705-706. doi: 10.1016/j.adro.2020.04.024

Romeo, A., Di Tella, M., Ghiggia, A., Tesio, V., Gasparetto, E., Stanizzo, M. R., et al. (2019). The traumatic experience of breast cancer: which factors can relate to the post-traumatic outcomes? Front. Psychol. 10:891. doi: 10.3389/fpsyg.2019. 00891

Romero, D. H., Riggs, S. A., and Ruggero, C. (2015). Coping, family social support, and psychological symptoms among student veterans. J. Couns. Psychol. 62, 242-252. doi: 10.1037/cou0000061

Rotter, J. B. (1966). Generalized expectancies for internal versus external control of reinforcement. Psychol. Monogr. 80, 1-28. doi: 10.1037/h0092976

Roussi, P., Krikeli, V., and Hatzidimitriou, C. (2007). Patterns of coping, flexibility in coping and psychological distress in women diagnosed with breast cancer. Cogn. Ther. Res. 31, 97-109. doi: 10.1007/s10608-006-9110-1

Russell, B. S., Hutchison, M., Tambling, R., Tomkunas, A. J., and Horton, A. L. (2020). Initial challenges of caregiving during COVID-19: caregiver burden, mental health, and the parent-child relationship. Child Psychiatry Hum. Dev. 51, 671-682. doi: 10.1007/s10578-020-01037-x

Ryan, R. M., and Deci, E. L. (2008). From ego depletion to vitality: theory and findings concerning the facilitation of energy available to the self. Soc. Personal. Psychol. 2, 702-717. doi: 10.1111/j.1751-9004.2008.00098.x

Sahar, N., and Muzaffar, N. (2017). Role of family system, positive emotions and resilience in social adjustment among Pakistani adolescents. J. Educ. Health Community Psychol. 6, 46-58. doi: 10.12928/jehcp.v6i2. 6944

Saita, E., Acquati, C., Fenaroli, V., Zuliani, C., and Bonanno, G. A. (2017). A confirmatory factor analysis of the perceived ability to cope with trauma (PACT) scale. TPM Test. Psychom. Methodol. Appl. Psychol. 24, 255-268. doi: 10.1037/ t13880-000

Sharif, S. P., and Khanekharab, J. (2017). External locus of control and quality of life among Malaysian breast cancer patients: the mediating role of coping strategies. J. Psychosoc. Oncol. 35, 706-725. doi: 10.1080/07347332.2017.130 8984
Smallheer, B. A., Vollman, M., and Dietrich, M. S. (2018). Learned helplessness and depressive symptoms following myocardial infarction. Clin. Nurs. Res. 27, 597-616. doi: 10.1177/1054773816689752

Smith, M. Y., Redd, W. H., Peyser, C., and Vogl, D. (1999). Post-traumatic stress disorder in cancer: a review. Psychooncology 8, 521-537. doi: 10.1002/(sici) 1099-1611(199911/12)8:6<521::aid-pon423<3.0.co;2-x

Stephens, J. P., Heaphy, E. D., Carmeli, A., Spreitzer, G. M., and Dutton, J. E. (2013). Relationship quality and virtuousness: emotional carrying capacity as a source of individual and team resilience. J. Appl. Behav. Sci. 49, 13-41. doi: $10.1177 / 0021886312471193$

Terraciano, A., McCrae, R. R., and Costa, P. T. Jr. (2003). Factorial and construct validity of the Italian positive and negative affect schedule (PANAS). Eur. J. Psychol. Assess. 19, 131-141. doi: 10.1027//1015-5759.19.2.131

Thakur, J. S. (2020). Novel Coronavirus pandemic may worsen existing global noncommunicable disease crisis. IJNCD 5, 1-3. doi: 10.4103/jncd.jncd_2_20

Thompson, C. A., Poelmans, S. A., Allen, T. D., and Andreassi, J. K. (2007). "On the importance of coping: a model and new directions for research on work and family," in Exploring the Work and Non-Work Interface: Research in Occupational Stress and Well Being, Vol. 6, eds P. Perrewe, and D. C. Ganster (Amsterdam: Emerald Press), 73-113.

Toscano, A., Blanchin, M., Bourdon, M., Antignac, A. B., and Sébille, V. (2020). Longitudinal associations between coping strategies, locus of control and health-related quality of life in patients with breast cancer or melanoma. Qual. Life Res. 29, 1271-1279. doi: 10.1007/s11136-019-02401-8

van de Haar, J., Hoes, L., Coles, C., Seamon, K., Fröhling, S., Jäger, D., et al. (2020). Caring for patients with cancer in the COVID-19 era. Nat. Med. 26, 665-671. doi: 10.1038/s41591-020-0874-8

Wallston, K. A., Wallston, B. S., and DeVellis, R. (1978). Development of the multidimensional health locus of control (MHLC) scales. Health Educ. Monogr. 6, 160-170.

Walsh, F. (1996). The concept of family resilience: crisis and challenge. Fam. Process $35,261-281$.

Weber, J. G. (2010). Individual and Family Stress and Crises. London: Sage. doi: $10.4135 / 9781452274720$

Westman, M., and Shirom, A. (1995). Dimensions of coping behavior: a proposed conceptual framework. Anxiety Stress Coping 8, 87-100. doi: 10.1080/ 10615809508249366

Williams, N. L. (2002). The Cognitive Interactional Model of Appraisal and Coping: Implications for Anxiety and Depression. Master's thesis, ProQuest Information \& Learning, Ann Arbor, MI.

World Health Organization (2020). Coronavirus Disease 2019 ( ${ }$ COVID-19) $\iota$ : Situation Report 114. Geneva: World Health Organization.

Yang, J., Zheng, Y., Gou, X., Pu, K., Chen, Z., Guo, Q., et al. (2020). Prevalence of comorbidities in the novel Wuhan coronavirus (COVID-19) infection: a systematic review and meta-analysis. Int. J. Infect. Dis. 94, 91-95. doi: 10.1016/ j.ijid.2020.03.017

Conflict of Interest: The authors declare that the research was conducted in the absence of any commercial or financial relationships that could be construed as a potential conflict of interest.

Copyright (C) 2021 Brivio, Guiddi, Scotto, Giudice, Pettini, Busacchio, Didier, Mazzocco and Pravettoni. This is an open-access article distributed under the terms of the Creative Commons Attribution License (CC BY). The use, distribution or reproduction in other forums is permitted, provided the original author(s) and the copyright owner(s) are credited and that the original publication in this journal is cited, in accordance with accepted academic practice. No use, distribution or reproduction is permitted which does not comply with these terms. 